\title{
MEMORIAL TO EDMOND MALINVAUD
}

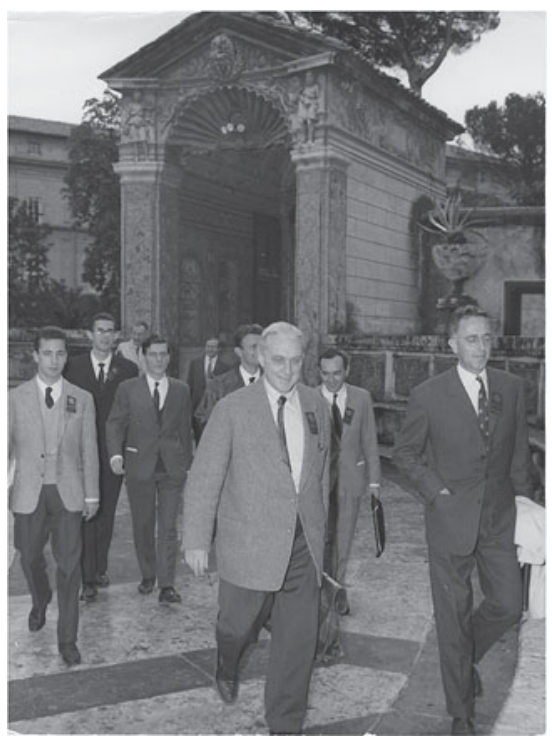

Twin Giants of Econometrics

Ragnar Frisch and Edmond Malinvaud striding forth at the famous Vatican Seminar ${ }^{1}$ in 1963. Photograph courtesy of the Frisch-Haavelmo Archive and Olav Bjerkholt, University of Oslo.

A great man, a wide-ranging thinker and writer, a pre-eminent researcher, and an inspiring educator passed away on 7 March 2015, leaving the world of economics so much the poorer and narrower. Edmond Malinvaud was a giant among many giants in the subject and one who strode uniquely and comfortably across the entire discipline like an academic colossus.

Malinvaud wrote three massively influential advanced textbooks on econometrics, microeconomic theory, and macroeconomics, thereby establishing his mastery of the full range of quantitative economics. His work in econometrics was inspirational, gripping readers in a passion for the subject that was founded in its freshness and vitality, its mathematical precision, and its links with deep empirical questions and matters of economic policy. His extraordinary treatise The Statistical Methods of Econometrics skilfully transported readers to the frontiers

1. "Study Week on the Econometric Approach to Development Planning" October 7-13 1963 held at the Pontifical Academy of Science in the Vatican City. 
of research in an elegant and rigorous passage that gave tantalizing glimpses of the possibilities that lay beyond present methods and thinking. Through brilliant exposition, comprehensive coverage, and its many novel developments, this work transcended its rival contemporaries as well as the many successor textbooks that emerged over subsequent decades. The book underwent translation from the original French edition and three major subsequent editions, revealing to readers of multiple generations the economic theory foundations, empirical relevance, and practical modelling concerns of econometrics. Malinvaud's understanding of advanced statistical method and the requisite probabilistic underpinnings of modern econometrics shone through its pages, positioning this book in a class of its own and richly rewarding every careful reading.

Econometrics is distinguished by the unifying power of ideas from economic theory, technique from mathematics, and methodology from statistics in guiding the empirical search for economic laws. This mantra inspired Malinvaud just as decades earlier it had motivated Ragnar Frisch, the founder of econometrics, and the first generation of econometricians. Its presence is felt strongly in the early chapters of Malinvaud's book, where Frisch himself figures prominently, and persists to the closing pages.

By virtue of his intellectual mastery and astonishing range, Malinvaud stood without equal in the French academy of economists for many decades in the mid $20^{\text {th }}$ century. It was a great honour for visitors to meet him in Paris - over lunches, within the famous eponymous Malinvaud seminar, and at various European conferences where his detached brilliance was always in evidence. In 1982 he visited Yale for the $50^{\text {th }}$ Cowles Anniversary celebrations and spoke of his vision of econometrics, its historical milestones over the previous half century, and its prospective future trajectories.

Malinvaud stands as one of the enduring figures of $20^{\text {th }}$ century economics. His passing is a sad and permanent loss to the French academy, to the profession at large, and to the world of econometrics where he reinstated in our discipline the rigor of the Cowles Commission researchers of the 1940s and delivered a unified thematic for the field that echoed the genius of Ragnar Frisch.

Malinvaud's memorial is his remarkable enduring contribution to our profession. His work and career were celebrated in an interview conducted by Alan Krueger (2003). He will be remembered by econometricians and by readers of Econometric Theory for his ET Interview (Holly and Phillips, 1987), with whose headnote laudation this memorial is best concluded:

Few economists indeed have the knowledge, the scientific expertise, and the professional experience to speak out with authority on the subject in its entirety and its scientific achievements. Even fewer command the respect of colleagues and authorities in neighboring disciplines, like mathematical statistics. For some time now, Edmond Malinvaud has stood out from the rest of our profession as a scholar who is uniquely qualified in this regard. His writings influence every 
field of economics. His advanced textbooks are cornerstones of graduate teaching programs. The scientific standards of his work set an example to the entire profession. And his recent evaluations of scientific accomplishments in quantitative economics have brought unity and direction to what was earlier just uncoordinated, individual research.

Peter C. B. Phillips

Yale University, University of Auckland, University of Southampton, and Singapore Management University

\section{REFERENCES}

Holly, A. \& P.C.B. Phillips (1987) The ET interview: Professor Edmond Malinvaud. Econometric Theory 3, 273-295.

Krueger, A. (2003). An interview with Edmond Malinvaud. Journal of Economic Perspectives 17, 181-198. 